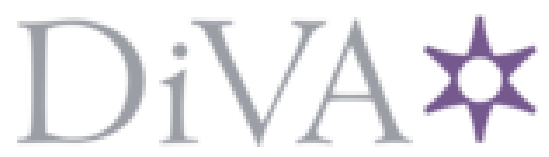

http://www.diva-portal.org

This is the published version of a paper published in Journal of materials engineering and performance (Print).

Citation for the original published paper (version of record):

Fu, Q., Lundin, D., Nicolescu, C. (2013)

Anti-vibration engineering in internal turning using a carbon nanocomposite damping coating produced by PECVD process.

Journal of materials engineering and performance (Print), : 1-12

http://dx.doi.org/10.1007/s11665-013-0781-y

Access to the published version may require subscription.

N.B. When citing this work, cite the original published paper.

Permanent link to this version:

http://urn.kb.se/resolve?urn=urn:nbn:se:kth:diva-122425 


\title{
Anti-vibration Engineering in Internal Turning Using a Carbon Nanocomposite Damping Coating Produced by PECVD Process
}

\author{
Qilin Fu, Daniel Lundin, and Cornel M. Nicolescu
}

(Submitted June 28, 2012; in revised form September 17, 2013)

\begin{abstract}
Machining dynamic stability has been enhanced through a damping coating based on a novel carbon-based nanocomposite material. The coating was synthesized using a plasma enhanced chemical vapor deposition method, and deposited on to the round-shank boring bar used for internal turning and tested during machining. Comparisons between an uncoated and a coated boring bar were carried out at $0.25 \mathrm{~mm}$ and $0.5 \mathrm{~mm}$ depth of cut using a five times length to diameter ratio overhang, which are typical conditions known to generate detrimental mechanical vibrations. From sound pressure measurement it was found that the measured absolute sound level during process could be reduced by about $90 \%$ when using the tool coated with damping layer. Surface roughness measurements of the processed workpiece showed decreased Ra values from approximately 3-6 $\mu \mathrm{m}$ to less than $2 \mu \mathrm{m}$ (and in $50 \%$ of the cases $<1 \mu \mathrm{m}$ ) when comparing an uncoated standard tool with its coated counterpart. Moreover, it was found that the addition of an antivibration coating did not adversely affect other tool properties, such as rigidity and modularity.
\end{abstract}

Keywords chatter, machining, vibration damping, coating, PECVD, HIPIMS, metal matrix composite, carbon nanocomposite

\section{Introduction}

Machined part's accuracy is affected by the static and dynamic behavior of the machining system. Chatter is a regenerative phenomenon caused by the relative movement between the cutting tool and the workpiece (Ref 1, 2). Once chatter arises, the machining process is considered unstable and negative effects such as breaking of the cutting tip, reduced tool life, and bad quality of the finished surface may occur (Ref 3 ). The severe damage caused by chatter during machining has been addressed by several research groups with the aim to dampen out harmful vibrations (Ref 1, 2, 4-12).

The different damping control techniques can be divided into two categories: active and passive damping (Ref 3 ). For active damping, real-time process data is acquired during operation and analyzed to generate signals, which will be used for controlling piezoelectric actuators (Ref 13). Passive damping control methods are implemented by using one of following techniques:

- Vibration absorbers,

- Vibration dampers,

Qilin Fu and CornelM. Nicolescu, Department of Production Engineering, School of Industrial Technique and Management, KTH Royal Institute of Technology, 10044 Stockholm, Sweden; and Daniel Lundin, Division of Space and Plasma Physics, School of Electrical Engineering, KTH Royal Institute of Technology, 10044 Stockholm, Sweden. Contact e-mail: qilin@kth.se.
- Tuned dampers,

- Interface damping treatments.

The vibration absorber method is used for systems with very low damping by externally adding a vibration absorber consisting of a mass-spring system (Ref 14). The damping effect of a vibration damper is produced through friction. An example of such a device is the Lanchester damper (Ref 14). Tuned dampers are used to minimize the amplitude of vibrations at some critical points of the structure. The purpose is to design a structural system with natural frequencies outside the frequency range of excitations (Ref 14).

For the interface damping treatment, viscoelastic materials are widely used as damping media because of the high damping property and the ease to apply on the interface of a structural element (Ref 15). The viscoelastic material has a high damping capacity independent of the strain, but the damping property depends on the vibration frequency and the temperature (Ref 15). The high damping of viscoelastic materials is due to relaxation and recovery of the long molecular chains that characterize the micro-structure of these materials (Ref 15).

Among other damping materials suitable for damping treatment that are considered in literature, carbon nanoparticles, and carbon nanotubes are nowadays drawing more attention because of the increased damping capacity and increased elasticity when applied to structural elements (Ref 16, 17). Analysis of the material damping correlated with microstructure of the material shows that an amorphous material with a large number of randomly oriented interfaces (due to, i.e., a granular composition) (Ref 18, 19), as well as defects in the material will increase the damping property of the material (Ref 16, 20, 21). It has also been found that when shear strain is induced in a vibrating medium, the material damping capacity is increased in comparison to cases where only bending strain is available (Ref 21). 
In this paper a new technology to produce a carbon-based, nanocomposite material, which is based on a novel plasmaenhanced chemical vapor deposition (PECVD) method (Ref 22), is introduced. The potential of the damping material produced by PECVD has been investigated in an internal turning machining process, where the material was applied as a thin coating on to a tool holder's clamping area. Comparisons between a coated and an uncoated tool were carried out in order to characterize the damping capacity under practical machining conditions as well as investigating the surface finish of the part machined for a wide range of both stable and unstable cutting conditions. Finally, the strain-dependent damping properties of the coating are also discussed.

\section{Experimental Details}

\subsection{Deposition Process}

A chemical vapor deposition (CVD) process that uses the energy from a plasma discharge, rather than thermal energy supplied by high process temperature (such as heating), to activate the gas phase chemistry is denoted Plasma-Enhanced CVD (PECVD) or alternatively Plasma-Activated CVD (PACVD) (Ref 23). A typical PECVD process used in the deposition process in this work is presented in Fig. 1.

In a PECVD process, the precursor gases are cracked by the energetic species in the plasma at a low overall process temperature, which means that low substrate temperatures can be used during deposition. This enables deposition on temperature sensitive substrates and the use of precursor gases with low reactivity. In this work, a power scheme using high-power pulses (HiPP) at a low duty factor $(<10 \%)$ and low frequency $(<1 \mathrm{kHz})$ has been applied in a magnetron configuration to generate pulsed process plasma discharges. It resulted in peak cathode power densities of about $0.1-1 \mathrm{~kW} \mathrm{~cm}^{-2}$, which is known to generate a highly energetic and highly ionized plasma (Ref 24). In such a PECVD process, the deposition conditions can be designed to provide a more reactive environment for the precursor gases, i.e., a higher deposition rate, as well as an energetic bombardment of the growing film, which affects the microstructure, phase formation and chemical composition (Ref 24). Further details of this plasma-based process are described elsewhere (Ref 22, 25).

For this purpose a standard planar rectangular magnetron with a surface area of $100 \times 450 \mathrm{~mm}^{2}$, equipped with a copper (99.9\%) target mounted in a cylindrical vacuum chamber (length $2000 \mathrm{~mm}$, diameter $1000 \mathrm{~mm}$ ) was used in the present experiments. The chamber was pumped by a turbo-molecular pump to a pressure of about $1.5 \times 10^{-3} \mathrm{~Pa}$, after which process gases (a mixture of argon, acetylene, and nitrogen) was let into the chamber. The process gas pressure was varied between 1 and $100 \mathrm{~Pa}$.

Unipolar pulses were applied between the cathode (magnetron with target) and the chamber walls in order to ignite a pulsed plasma discharge using an in-house developed power supply capable of delivering $2000 \mathrm{~V}$ and $200 \mathrm{~A}$ peak values. In this work, pulses up to approximately $600 \mathrm{~V}$ and $80 \mathrm{~A}$ (equivalent to a peak current density of about $0.17 \mathrm{~A} \mathrm{~cm}^{-2}$ ) were used with a pulse duration of $400 \mu \mathrm{s}$ and a repetition frequency of $300 \mathrm{~Hz}$. Basic plasma parameters such as target voltage and target current were monitored and recorded on an Agilent DSO1004A oscilloscope. A Tektronix P6007 high voltage probe measured the target voltage. The current was

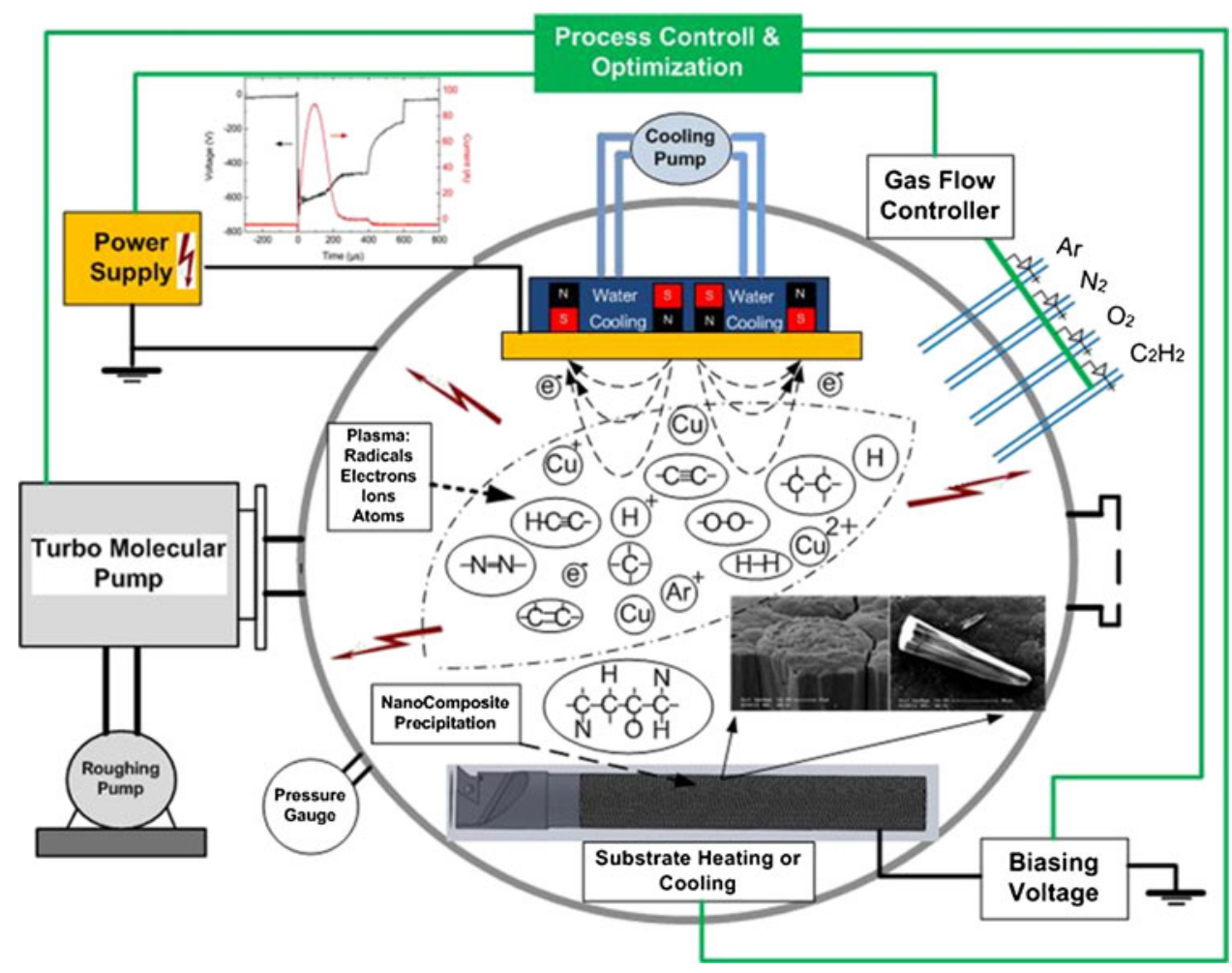

Fig. 1 A typical schematic view of the PECVD process used in this work. A turbo-molecular vacuum pump is used for reaching a low background pressure. A pulsed high-power supply is connected to the magnetron, which acts as a cathode. The magnetron will magnetically confine the discharge and will thereby aid in the ignition of the plasma. The workpiece is placed in a rotating substrate holder below the cathode 
measured with a Chauvin Arnoux C160 current probe. A typical discharge voltage and current measurement is shown in Fig. 2.

The resulting carbon-based coating was deposited on a boring bar (made of tool steel; for details see "Material Properties " section) used in the machining tests, as well as on pure silicon substrates used in the characterization of the coated material. All depositions were carried out at ambient temperature without external substrate heating. The position of the substrates was approximately $18 \mathrm{~cm}$ away from the cathode surface. A motor was used to rotate the substrates at a continuous speed of $1.3 \mathrm{rpm}$. After deposition, the thickness and microstructure of the deposited coating were studied using a LEO scanning electron microscope (SEM) on cleaved $\mathrm{Si}$ samples. The elemental composition was investigated in parallel by energy-dispersive X-ray spectroscopy (EDX) using the same instrument. The film hardness was investigated by nano-indentation (Triboscope ${ }^{\circledR}$, Hysitron Inc.).

\subsection{Material Properties}

The carbon-based nanocomposite coating achieved by using the above described deposition process can be seen in the scanning electron microscope (SEM) micrograph presented in Fig. 3, where it was deposited onto a pure silicon sample. The microstructure shows porous columns exhibiting competitive growth among the different grains. Typical thickness of the deposited layer is $400 \mu \mathrm{m}$ and the maximum documented thickness is $600 \mu \mathrm{m}$. From SEM measurements it was deducted that the damping coating can, in the present setup, be grown at a deposition rate of about $15 \mu \mathrm{m} / \mathrm{h}$, which is at least an order of magnitude greater than what can be achieved using conventional magnetron deposition methods sputtering carbon (Ref 26).

From the deposited silicon samples the hardness was found to be about $0.5 \mathrm{GPa}$ measured using nano-indentation. From the same measurements the friction coefficient of the coating was estimated to about $0.25-0.35$.

\subsection{Machining Set Up Details}

Two identical round shanked boring bars (made of tungsten steel) of $25 \mathrm{~mm}$ in diameter were chosen for the tests. In one case the end section of the boring bar was ground down $400 \mu \mathrm{m}$ in radius and coated with an equally thick layer of the

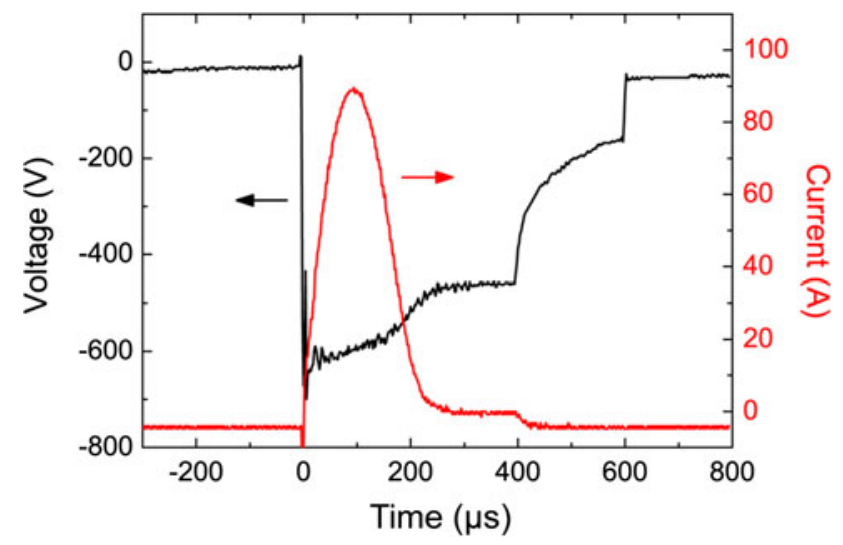

Fig. 2 The measured voltage and current on the cathode during the pulsed PECVD discharge process carbon-based nanocomposite material, as shown in Fig. 4. Before machining, the dynamic properties of both the coated and uncoated tools were investigated by modal analysis on the tool tip in the direction of cutting speed on the insert. An impact hammer (Dytran Model 5800SL S/N4845) was used to make the measurement, and one accelerometer was waxed to the tool tip to acquire the acceleration data.

An internal turning process using the boring bar with a five times length to diameter overhang was chosen to investigate the machining performance with regards to stability, owing to the fact that the stability limit for a conventional boring bar is approximately five times the length to diameter (Ref 27). The regenerative tool chatter during machining process will occur if the depth of cut exceeds the critical depth of cut limit (Ref 2, 12). To define the stability limit, both static stiffness and damping are important for specifying the stability lobe diagram (Ref 2). The stability limit for a certain spindle speed is calculated by Eq (2.1):

$a p=-\frac{1}{2 K_{\mathrm{f}} * G(w)}$

where $K_{\mathrm{f}}$ represents the workpiece material's cutting resistance and $G(w)$ represents the real negative part of the transfer function between the tool and workpiece.

When an internal turning tool possess five times free hanging length $(125 \mathrm{~mm})$ to diameter $(25 \mathrm{~mm})$ ratio and $1 \%$ mode damping ratio, the stability diagram can be calculated by defining the workpiece material's specific cutting force with $3000 \mathrm{MPa}$ (Ref 28), as shown in Fig. 5.

In Fig. 5 when the cutting depth exceeds the limits defined by the stability lobes, the machining process will be un-stable, and the overall limit is low as $0.017 \mathrm{~mm}$. A normal machining process will easily exceed the limit and result in an unstable machining process. In reality, the machining condition about regenerative chatter, especially regarding the workpiece material's specific cutting force, also depends on the insert geometry, feed rate, rake angle and clearance angle, etc. (Ref 29). The process damping caused by the friction between the insert's flank face and workpiece material will also affect the machining process's stability From an experimental point of view, the conventional way used is to find the minimum stability limit by machining operations (Ref 30).

Both the conventional tool and the coated tool were clamped in the same fixture and under the same clamping conditions. A standard VDI (Verein Deutscher Ingenieure, the Association of German Engineers) tool holder with an inner diameter of $42 \mathrm{~mm}$ was used as the clamping interface to the machine turret. A collet with inner diameter $25 \mathrm{~mm}$ and outer diameter $42 \mathrm{~mm}$ was used between the tool and the standard VDI tool holder. Figure 6 gives an overview of the conventional tool, the damped tool, the collet, as well as the standard VDI tool holder.

As seen in Fig. 6, on the standard VDI tool holder there are three clamping screws where the tool can be clamped in the collet. The clamping torque for all of the screws was pre-set to be $40 \mathrm{Nm}$ so as to have the same clamping conditions.

Since the spindle speed of the cutting process is important for triggering chatter as indicated by NIGM (Ref 31), each cutting process was started at $800 \mathrm{rpm}$, then increased gradually to $960 \mathrm{rpm}$, and finally reduced to $640 \mathrm{rpm}$. By doing so, the whole spindle speed range of 640-960 rpm was covered in order to test the stability limit. The cutting speed will be dependent on the inner diameter of the workpiece. Furthermore, 


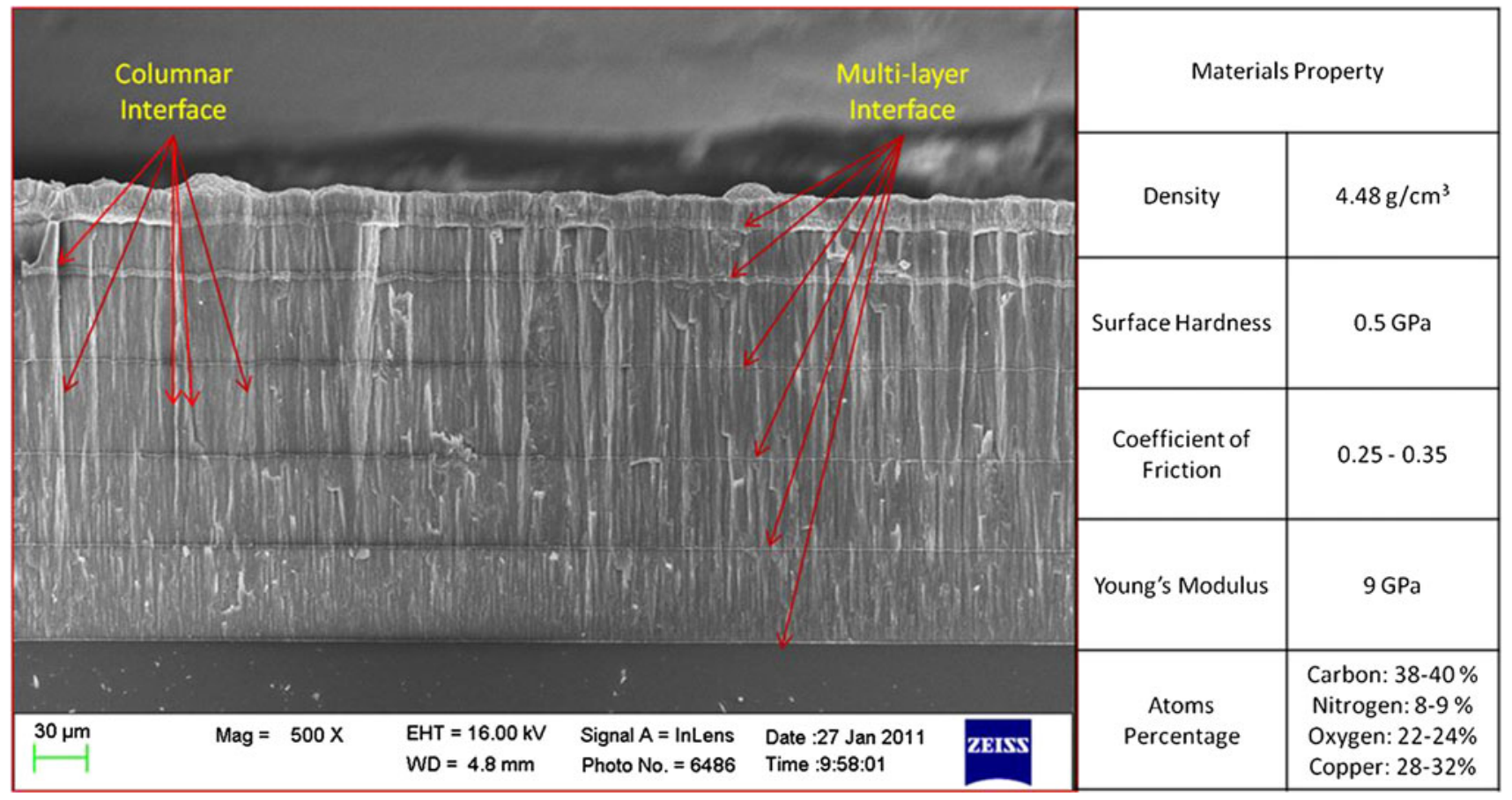

Fig. 3 Cross-section SEM micrograph of the carbon-based nanocomposite layer (top) coated on top a silicon sample (bottom). An adhesion pre-layer of a few micrometers is also seen in the middle

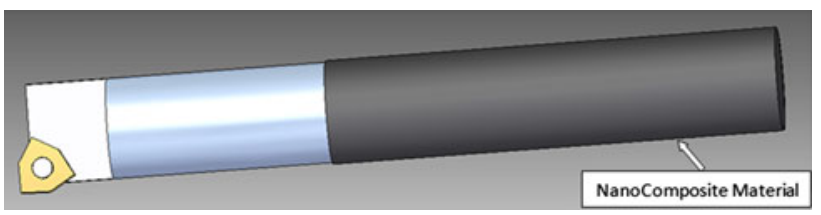

Fig. 4 Schematic showing the design concept of the internal turning tool with the carbon-based nanocomposite layer coated on top (right end of the tool)

during the tests of the machining stability, each cutting sequence was repeated three times using the same depth of cut, since chattering has a tendency to be affected by the pre-cut surface texture.

The nose radius of the insert was $0.4 \mathrm{~mm}$ with a feed rate of $0.15 \mathrm{~mm} / \mathrm{rev}$. For each new test sequence in the turning tests, a new insert was used to avoid disturbance caused by wear land of the cutting edge. The workpiece was made of a steel cylinder with diameter $126 \mathrm{~mm}$, length $170 \mathrm{~mm}$. Before the experiment, a diameter $39 \mathrm{~mm}$ hole had been drilled throughout the center. The cutting material was ISO 4340(SS2541), and the machining process was performed on the same workpiece to eliminate material inhomogeneity that might show up between different workpieces. The tool path length was $85 \mathrm{~mm}$ in the feed direction.

During machining, the sound pressure was recorded by a microphone mounted at a remote enough distance from the machining area, so that the influence of the tool travel path can be neglected (i.e., the distance microphone-machining area is assumed to be constant). The voltage output from the microphone was recorded to compare the sound signal emitted from different process conditions, since the transmitted sound from a cutting process is strongly related to the vibration conditions of the structure. Furthermore, the power spectrum of measured sound signal was also recorded, since it is an indication of what vibration modes that arise during operation.

After the machining process, photos were taken of the surface of the machined part and the surface roughness was measured on three different positions on the surface to calculate the average Ra values (Surftest SJ-400 Series 178-Portable Surface Roughness Tester, Mitutoyo).

\section{Results}

\subsection{Modal Analysis of the Boring Bars}

In order to determine the dynamic properties of both the damped tool and the conventional tool, modal analysis on the tool tip in the direction along the cutting speed direction on the insert was performed to obtain the modal characteristics. The approach has previously been described by Andren et al. (Ref 32), where they investigated the vibration properties of an internal turning process. In that study, it was also confirmed that the most critical chatter is in the cutting speed direction. The first vibration modal parameters of both the conventional tool and the coated tool clamped in the VDI tool holder are shown in Table 1.

From the FRF plots, the stiffness values were calculated and are shown in Table 1. From the measurements it is seen that both tools have almost the same rigidity, although the coated tool has a slightly lower first mode frequency. Note that, the damping ratio measurement also shows that both tools have almost the same amount of damping for the given clamping conditions. However, consideration has to be paid to the triggering force being small when using the impact hammer, which is further discussed in "The Observation of Modal Analysis Results" section. 

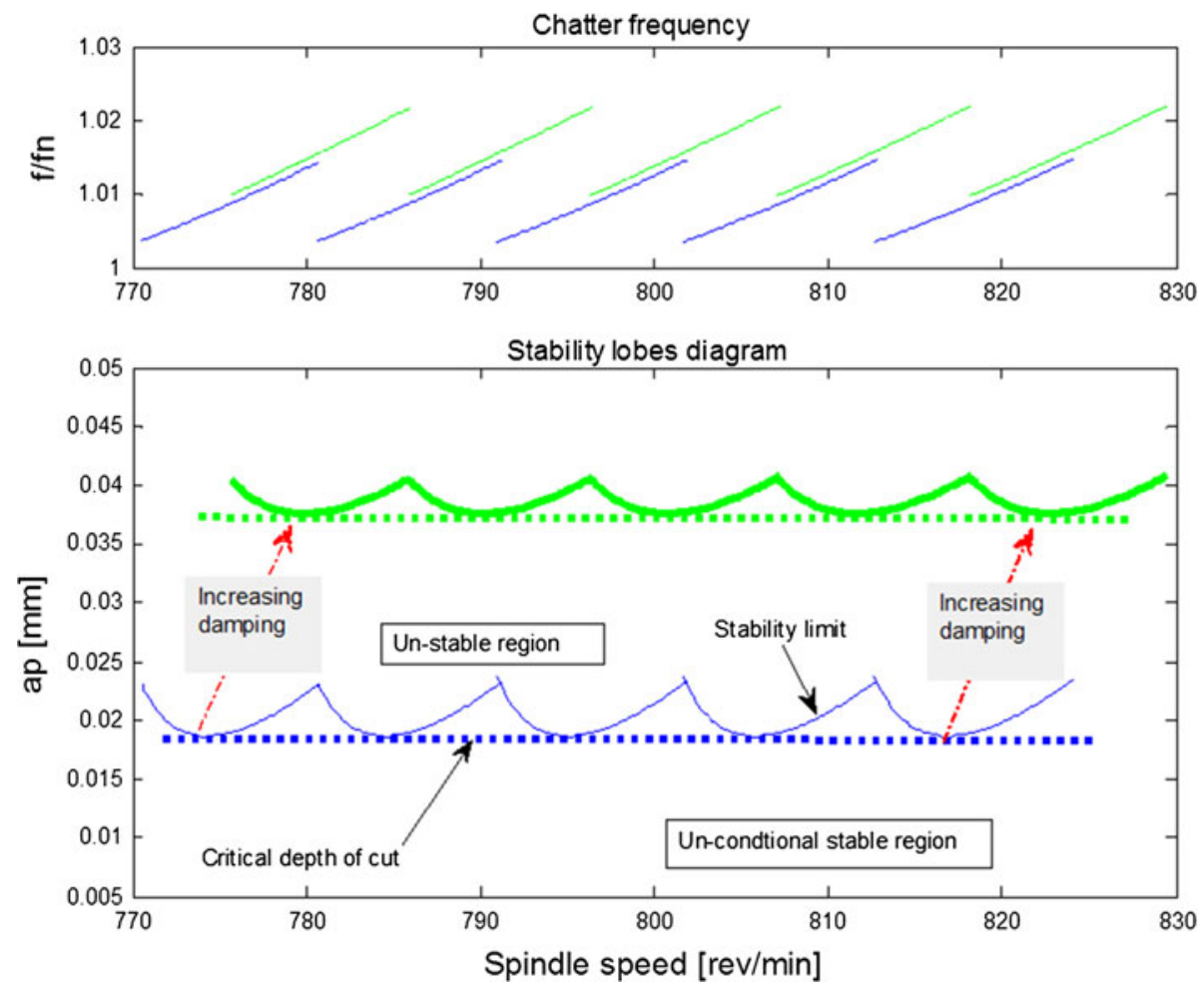

Fig. 5 The blue curve represents an example of stability lobes of a 125 -mm-free hanging tool, with 25 -mm diameter and $1 \%$ mode damping ratio, $0.15 \mathrm{~mm} / \mathrm{rev}$ feed, and $3000 \mathrm{MPa}$ as the work piece material's specific cutting force, the green curve represents another example with the same set up except for the mode damping ratio has increased to $2 \%$

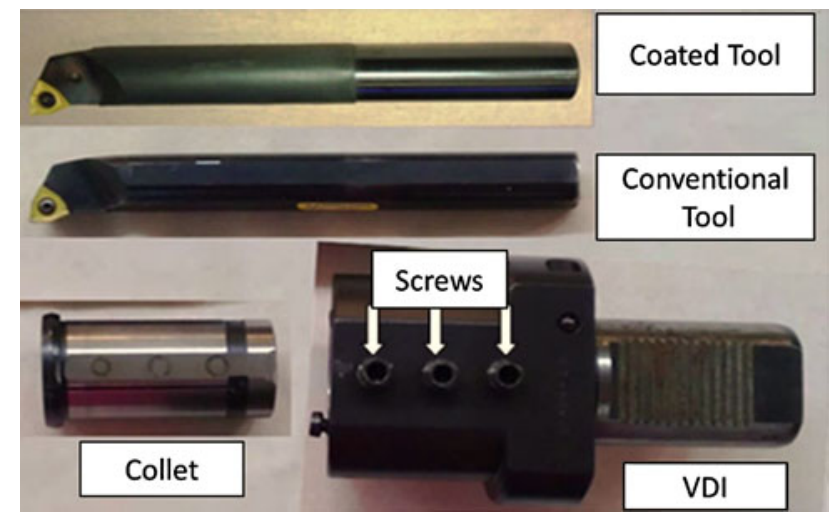

Fig. 6 The coated and uncoated conventional tools along with the collet and the VDI used in the turning tests

Furthermore, the power spectrum of the sound signal during the machining process was also analyzed (not shown here). It was found that the energy is mainly concentrated at a frequency band which is close to the first mode frequency at approximately $970 \mathrm{~Hz}$. The power spectrum analysis also shows some other frequency bands at higher frequencies. However, the measured voltage amplitudes on those frequency bands are much lower in comparison to the first mode. Those frequency bands are believed to be related to the harmonics of the first mode frequency, since they show up at frequencies of $n$ times the first mode frequency, where $n$ is a positive integer (Ref 34).

\subsection{Machining Results}

The recorded sound signal for both the conventional tool, and the coated tool, with $0.25 \mathrm{~mm}$ and $0.5 \mathrm{~mm}$ depth of cut, is shown in Fig. 7. The cutting parameters are summed up in Table 2.

From the measured voltage output of the microphone in Fig. 7, it is shown that during a machining process performed by a conventional uncoated tool the maximum voltage output was around $40 \mathrm{~V}$ and the maximum voltage output of the coated tool was around $5 \mathrm{~V}$, where the last measurement was very close to the value when measuring the background sound level from the workshop (i.e., the sound emitted by the machine spindles, gear transmissions, pumps, and so on).

When the depth of cut was $0.25 \mathrm{~mm}$, the conventional tool was strongly vibrating, which was revealed by strong oscillations in the sound pressure measurement during the machining test. Since the insert was moving in and out the workpiece, the insert tip always broke during the process due to the dynamic thrust force. It can be observed from the top left graph in Fig. 9 that during machining, the insert tip breaks in the middle of the process and leaves a rather smooth surface during the second half of the process. When the depth of cut was $0.5 \mathrm{~mm}$, the insert of the uncoated tool did not break, but it was severely worn down, as observed by the naked eye. In the case of the coated tool the cutting inserts, under the conditions shown in Fig. 9, were still in good condition and could have been used again if needed.

In order to find the cutting limit of the coated tool, the cutting depth was increased to $1 \mathrm{~mm}$, and finally $1.5 \mathrm{~mm}$, with $800 \mathrm{rpm} \pm 20 \%$, using the same workpiece. The cutting process data is available in Table 2, and the recorded sound signal is shown in Fig. 8. Note that, the uncoated tool could not be operated in this range. We have, however, for comparison added the previously recorded sound signal for the $0.5 \mathrm{~mm}$ depth of cut using the uncoated tool (red signal). The maximum 
Table 1 Modal information obtained from the synthesized receptance FRF (Ref 33) for the conventional uncoated tool and the coated tool

\begin{tabular}{lcccc}
\hline & $\boldsymbol{M}$ (mass, kg) & $\boldsymbol{K}$ (stiffness, N/m) & $\boldsymbol{f}_{\boldsymbol{n}}\left(\mathbf{1}^{\text {st }}\right.$ mode frequency) (Hz) & $\xi(\mathbf{d a m p i n g ~ r a t i o )}$ \\
\hline Conventional uncoated tool & 0.066 & $2,519 \mathrm{E} 6$ & 981 & $0.86 \%$ \\
Coated tool & 0.063 & $2,358 \mathrm{E} 6$ & 977 & $0.77 \%$ \\
\hline
\end{tabular}
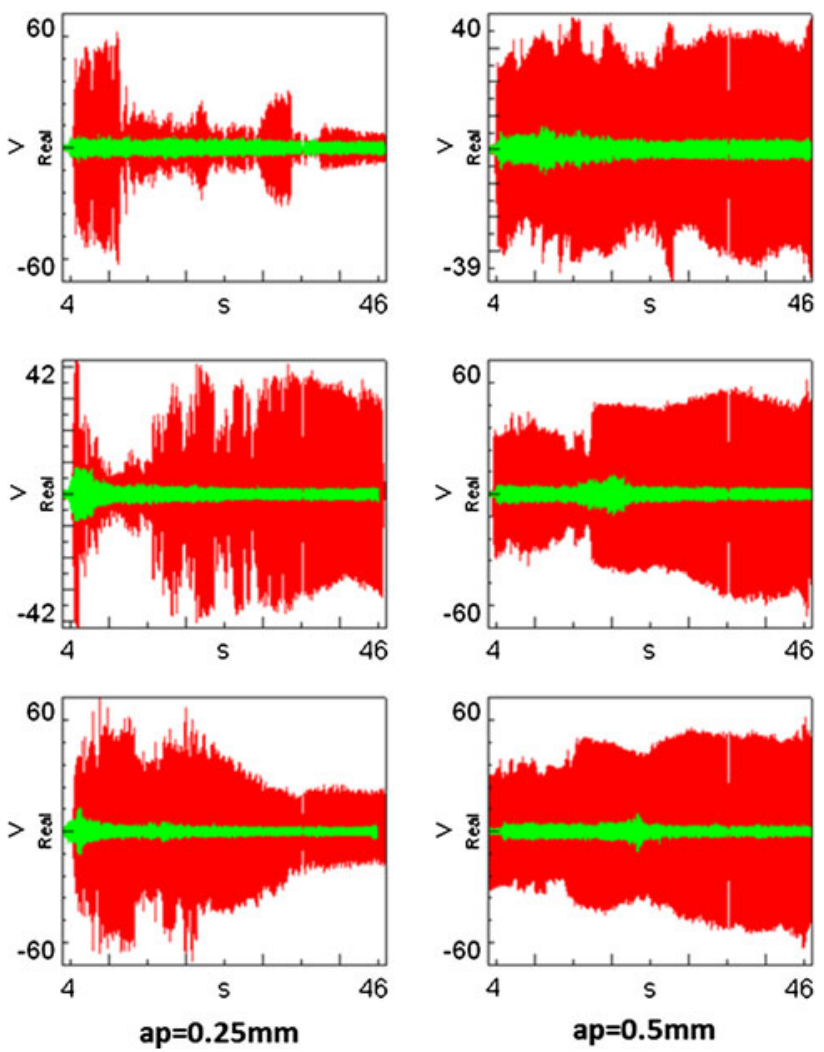

Fig. 7 The recorded sound signal vs. time for the conventional tool (red color), and the coated tool (green color), with $0.25 \mathrm{~mm}$ depth of cut (to the left) and $0.5 \mathrm{~mm}$ depth of cut (to the right)

depth of cut was set at $1.5 \mathrm{~mm}$ during the experiment since the machining process was already unstable at $1.5 \mathrm{~mm}$ depth of cut. This indicates that the overall minimum stability limit for depth of cut with the coated tool is less than $1.5 \mathrm{~mm}$.

The surface finish of the machined workpiece was visually inspected. In Fig. 9, we present photos displaying the surface texture after using the uncoated tool (top) as well as the coated tool (bottom) for $0.25 \mathrm{~mm}$ depth of cut. For each tool the same cutting sequence was repeated three times in order to insure better statistics, as previously discussed in "Material Properties". Furthermore, the same procedure was repeated for $0.5 \mathrm{~mm}$ depth of cut and the results are given in Fig. 10 .

The surface finish of the coated tool with $1 \mathrm{~mm}$ depth of cut and $1.5 \mathrm{~mm}$ depth of cut is summarized in Fig. 11.

It was observed during machining, when the depth of cut reaches $1.5 \mathrm{~mm}$, the coated tool was unstable in the spindle range of 640-800 rpm, and left marks on the surface because of vibrations from the tool as shown by the red arrows in Fig. 11.

Finally, from the data recorded in the surface roughness test comparison between the coated and the uncoated tools at 0.25 and $0.5 \mathrm{~mm}$ depth of cut the $R a$ values are summarized in
Fig. 12. For completeness, we have in Fig. 12 also added the Ra values for $1.0 \mathrm{~mm}$ and $1.5 \mathrm{~mm}$ depth of cut in the case of the coated tool.

Here, it should be noted that the surface finish of a stable machining process depends to a large extent on the feed rate of machining process and insert tip geometry. The idealized peak to valley surface roughness was calculated referring to the technical guidance of a turning process (Ref 35$)$ :

$$
R_{\max }=\frac{f^{2}}{8 r}=\frac{0.15^{2}}{8 \times 0.4} \mathrm{~mm}=7.03 \mu \mathrm{m} .
$$

The surface profile measurement result indicates that, a coated boring bar can produce a surface finish, which is in the range of the specified idealized peak to valley surface roughness, whereas the surface produced by a conventional, uncoated boring bar has a value of about $40-50 \mu \mathrm{m}$.

As the surface roughness of the contact surfaces in the mechanical structure's interface will have some effect on the damping behavior of the cutting tool (Ref 36), the surface roughness measurements for the conventional uncoated tool, the coated tool, and the collet are summarized in Table 3.

It can be observed that the coated tool has a slightly higher surface roughness in comparison to the conventional tool, but under the same clamping conditions the interface damping will not change dramatically and we do not expect any significant impact on the damping tests.

\section{Discussion}

\subsection{The Observation of Modal Analysis Results}

From the measurement of the frequency response functions, and modal analysis, we observed very little difference between the coated tool and the conventional uncoated tools, as seen in Table 1. However, it is suggested that the commonly observed non-linear behavior of the damping capacity vs. stress (Ref 21), where a too low stress will generate negligible damping, is the reason for the results presented here. Not enough force can be delivered, since the mass of the impact hammer is only $10 \mathrm{~g}$ and thus the peak force delivered in a single impulse excitation is limited to about $27 \mathrm{~N}$. Thus, it is therefore believed that these measurements solely cannot adequately resolve the behavioral differences that might arise when applying the coating onto the tool. In order to characterize the material damping properties of this coating, it is therefore necessary to conduct additional tests such as the ones described in this work. It also highlights the fact that any damping effects must be investigated under real machining conditions, since the forces applied will be considerably higher (several hundred Newton) than those delivered by the hammer, and thus the non-linear behavior of this material will be easier to observe.

On the other hand, the data in Table 1 shows that both the coated tool and the conventional tool have almost the same 
Table 2 Cutting process parameters used in the machining tests of the conventional uncoated tool and the coated tool

\begin{tabular}{|c|c|c|c|c|c|}
\hline & Run no. & $\begin{array}{c}\text { Depth of } \\
\text { cut, ap, }(\mathbf{m m})\end{array}$ & $\begin{array}{l}\text { Workpiece inner } \\
\text { diameter (mm) }\end{array}$ & $\begin{array}{l}\text { Spindle speed } \\
(\mathrm{r} / \mathrm{min})\end{array}$ & $\begin{array}{c}\text { Cutting speed } \\
(\mathrm{m} / \mathrm{min})\end{array}$ \\
\hline \multirow[t]{6}{*}{ Conventional uncoated tool } & 1 & 0.50 & 40 & $800 \pm 20 \%$ (5 \% step $)$ & $100.53 \pm 20 \%$ \\
\hline & 2 & 0.50 & 41 & $800 \pm 20 \%(5 \%$ step $)$ & $103.04 \pm 20 \%$ \\
\hline & 3 & 0.50 & 42 & $800 \pm 20 \%(5 \%$ step $)$ & $105.56 \pm 20 \%$ \\
\hline & 9 & 0.25 & 50.5 & $800 \pm 20 \%(5 \%$ step $)$ & $126.92 \pm 20 \%$ \\
\hline & 10 & 0.25 & 51 & $800 \pm 20 \%(5 \%$ step $)$ & $128.18 \pm 20 \%$ \\
\hline & 11 & 0.25 & 51.5 & $800 \pm 20 \%(5 \%$ step $)$ & $129.43 \pm 20 \%$ \\
\hline \multirow[t]{8}{*}{ Coated tool } & 4 & 0.50 & 43 & $800 \pm 20 \%(5 \%$ step $)$ & $108.07 \pm 20 \%$ \\
\hline & 5 & 0.50 & 44 & $800 \pm 20 \%(5 \%$ step $)$ & $110.58 \pm 20 \%$ \\
\hline & 6 & 0.50 & 45 & $800 \pm 20 \%(5 \%$ step $)$ & $113.10 \pm 20 \%$ \\
\hline & 7 & 1.00 & 47 & $800 \pm 20 \%(5 \%$ step $)$ & $118.12 \pm 20 \%$ \\
\hline & 8 & 1.50 & 50 & $800 \pm 20 \%(5 \%$ step $)$ & $125.66 \pm 20 \%$ \\
\hline & 12 & 0.25 & 52 & $800 \pm 20 \%(5 \%$ step $)$ & $130.69 \pm 20 \%$ \\
\hline & 13 & 0.25 & 52.5 & $800 \pm 20 \%(5 \%$ step $)$ & $131.95 \pm 20 \%$ \\
\hline & 14 & 0.25 & 53 & $800 \pm 20 \%(5 \%$ step $)$ & $133.20 \pm 20 \%$ \\
\hline
\end{tabular}
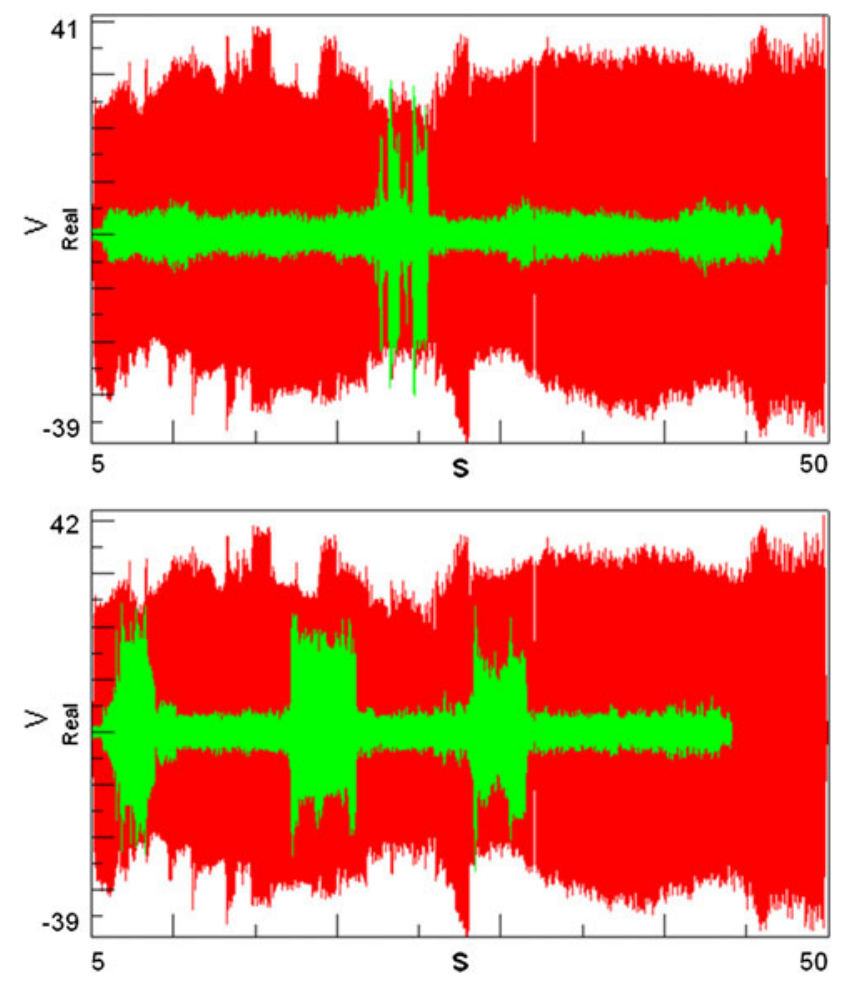

Fig. 8 The recorded sound signal from the machining process using a coated tool (green curve) at $1 \mathrm{~mm}$ depth of cut (top) and $1.5 \mathrm{~mm}$ depth of cut (bottom). For simple comparison the sound signal using a conventional, uncoated tool, at $0.5 \mathrm{~mm}$ depth of cut has been superimposed (red curve). Note that, the latter tool could not be operated at higher depths of cut

stiffness (revealed by the first mode frequency), meaning that by adding the carbon-based nanocomposite coating, the overall stiffness of the tool is not significantly changed which is an advantage under real machining conditions.

It is important to note that the weakest part in the machine structure is the tool shank, because the overhang length $(125 \mathrm{~mm})$ is five times the diameter $(25 \mathrm{~mm})$ of the tool. To avoid any vibrational problems from the workpiece itself we chose a rigid enough workpiece in the experiments reported here. By correlating the sound power spectrum to the results generated by the impact hammer it was found that the bulk part of the energy is in both cases located at the same frequency $(\sim 1000 \mathrm{~Hz})$. Therefore, the accordance between the measured sound power spectrum frequency band and the first vibrational mode of the tool can safely be used as an indicator of vibrations arising at the location of the tool shank during the machining process.

\subsection{The Sound Pressure and the Surface Roughness}

The transmitted sound from a cutting process is, as previously stated in "Experimental Details" section, strongly related to the vibration conditions of the structure and hence a good indicator of whether one is operating in a stable regime. Furthermore, strong generation of sound emitted from the machining process can be very harmful to the operator, and the trend is to reduce the sound level in many production plants. From Fig. 7 and the results described in "Machining Results" it is seen that by using the coated tool it is possible to reduce the measured absolute signal of the sound pressure by about $90 \%$, which clearly indicates an improvement of the operating conditions.

Further analysis of the recorded experimental data along with observations from the operations shows that, with $1 \mathrm{~mm}$ depth of cut for the coated tool (Fig. 8, top), the spindle range of 640-720 rpm is showing up to be unstable, but still can be adjusted to fall back to the stable region. When the depth of cut is $1.5 \mathrm{~mm}$ for the coated tool (Fig. 8, bottom), the spindle range of $640-800 \mathrm{rpm}$ is showing up to be unstable, but still can be adjusted to fall back to the stable region. The power spectrum analysis (not shown here) was also performed on the results presented in Fig. 8, and it was found that the resonance frequency band where the machining process is unstable is close to the first mode frequency of the tool at around $970 \mathrm{~Hz}$, which means that any vibration problems are related to the tool also at these higher depth of cuts. No further tests were performed at these higher values of depth of cut, since the comparison with data from the uncoated tool was not possible as previously described.

From the processed workpieces machined by the uncoated and coated tools we could by measuring the surface finish, $R a$, evaluate the effect of coating to dampen out the above described harmful vibrations during machining. The nominal value of the surface finish value for a turning process is around 


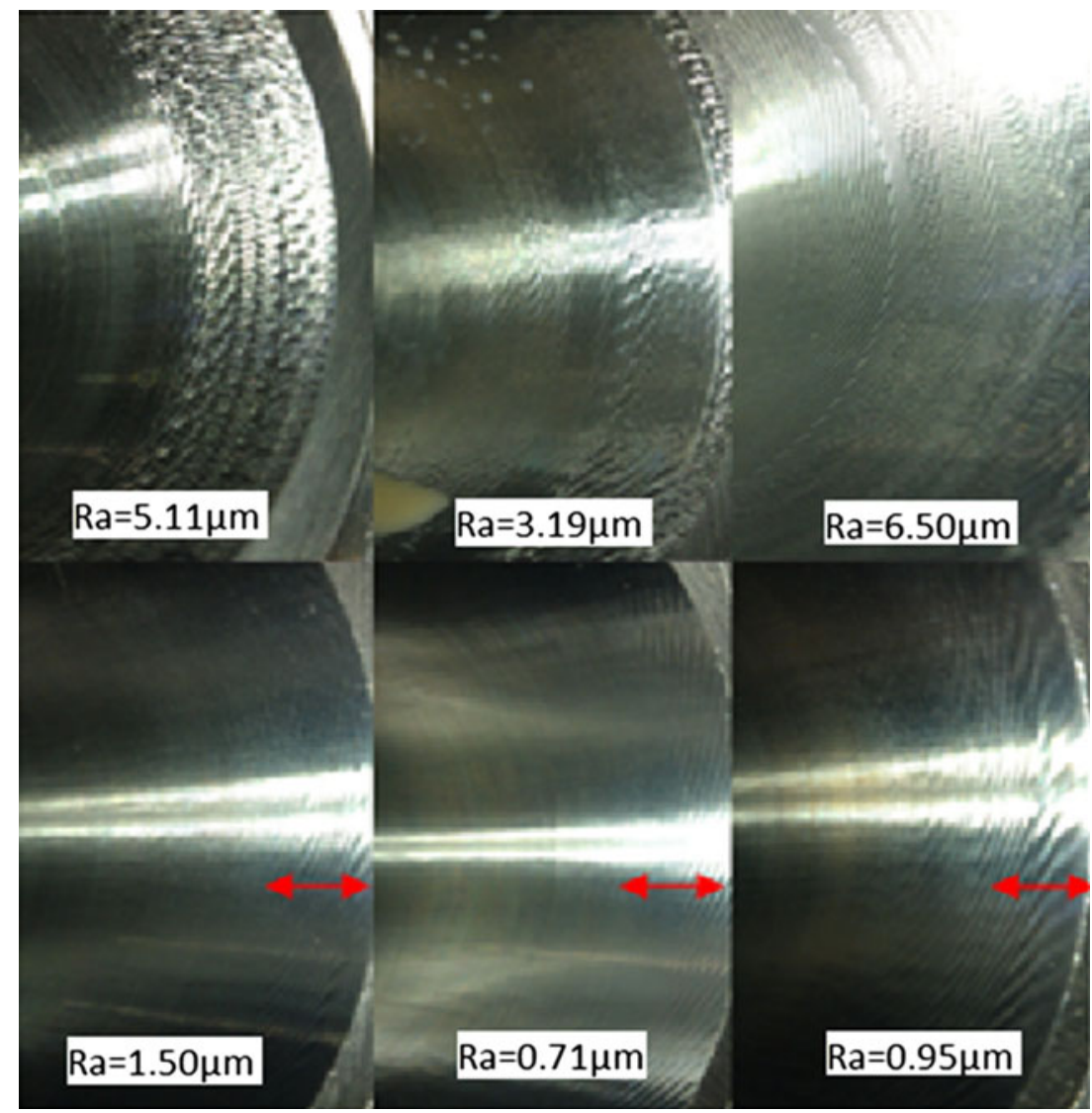

Fig. 9 Surface finish of the workpiece after machining using the conventional uncoated tool (top), as well as the coated tool (bottom). The depth of cut was in all cases $0.25 \mathrm{~mm}$ and the same cutting sequence was repeated three times for each tool. The surface roughness value is an averaged value of measurements at three different points

1-2 $\mu \mathrm{m}$ (Ref 37), and this is the range which is commonly accepted within the industry. From the results presented in Fig. 12 it is found that all of the surface roughness measurements performed on the workpiece machined by the coated tool are below the critical limit of $2 \mu \mathrm{m}$ and half of them are below $1 \mu \mathrm{m}$. When using the uncoated conventional tool the values are all above $3 \mu \mathrm{m}$ and most of them are around $5 \mu \mathrm{m}$ or higher, which indicates an unstable machining process, and does not meet the required specifications of the end product. There is also a possibility that the measurements hit the upper limit of what is possible to measure using the needle-based surface roughness technique, which implies that for the uncoated tool we might even reach higher $R a$ values than what is reported here.

Due to the fact that stable operating conditions were met for the coated tool using both 0.25 and $0.50 \mathrm{~mm}$ depth of cut, additional machining tests were conducted with 1 and $1.5 \mathrm{~mm}$ depth of cut (Fig. 8, 11). From these tests it was observed that the coated tool has a critical depth of cut of $1 \mathrm{~mm}$. As the depth of cut increases, more and more spindle ranges will be marked as unstable, which can be seen in the bottom part of Fig. 8. This complies well with the stability lobe theory, since the critical depth of cut depends on the spindle speed, and the higher the depth of cut the more likely that the process is unstable (Ref 1 , 2).

In summary, from both Fig. 9 and 10, it is clearly observed that the surface finish with the conventional uncoated tool results in a failed product because the surface is damaged due to chatter from the tool, and the coated tool results in a better surface finish quality. However, from Fig. 9 (0.25 mm depth of cut), it can be seen that when the coated tool is under operation, during the entrance of the cutting process, the tool left some fringes as pointed out by the red lines on the surface. This kind of fringes cannot be found when the depth of cut is $0.5 \mathrm{~mm}$, and it is probably because the coated tool needs to be subjected to a high enough force to work with in order to reach a certain strain in the material to provide damping, which can guarantee stable behavior of the cutting process (see also the discussion on non-linear damping in the beginning of "The Observation of Modal Analysis Results" section). Further investigations have to be implemented to study this phenomenon.

\subsection{Properties of the Damping Material}

From the results presented above it is concluded that the carbon-based nanocomposite material coated onto a tool has a beneficial effect when it comes to reducing harmful vibrations. The working principle of the approach used in the present study is to deposit a damping material, which possesses a high elasticity, and place it at the areas where the maximum vibration strain energy will be concentrated, as previously investigated for other passive damping applications ( $\operatorname{Ref} 8,38$ ). With a similar design to that of Lorenzo et al. (Ref 8), the damping material is applied to the area where the tool end is clamped. 


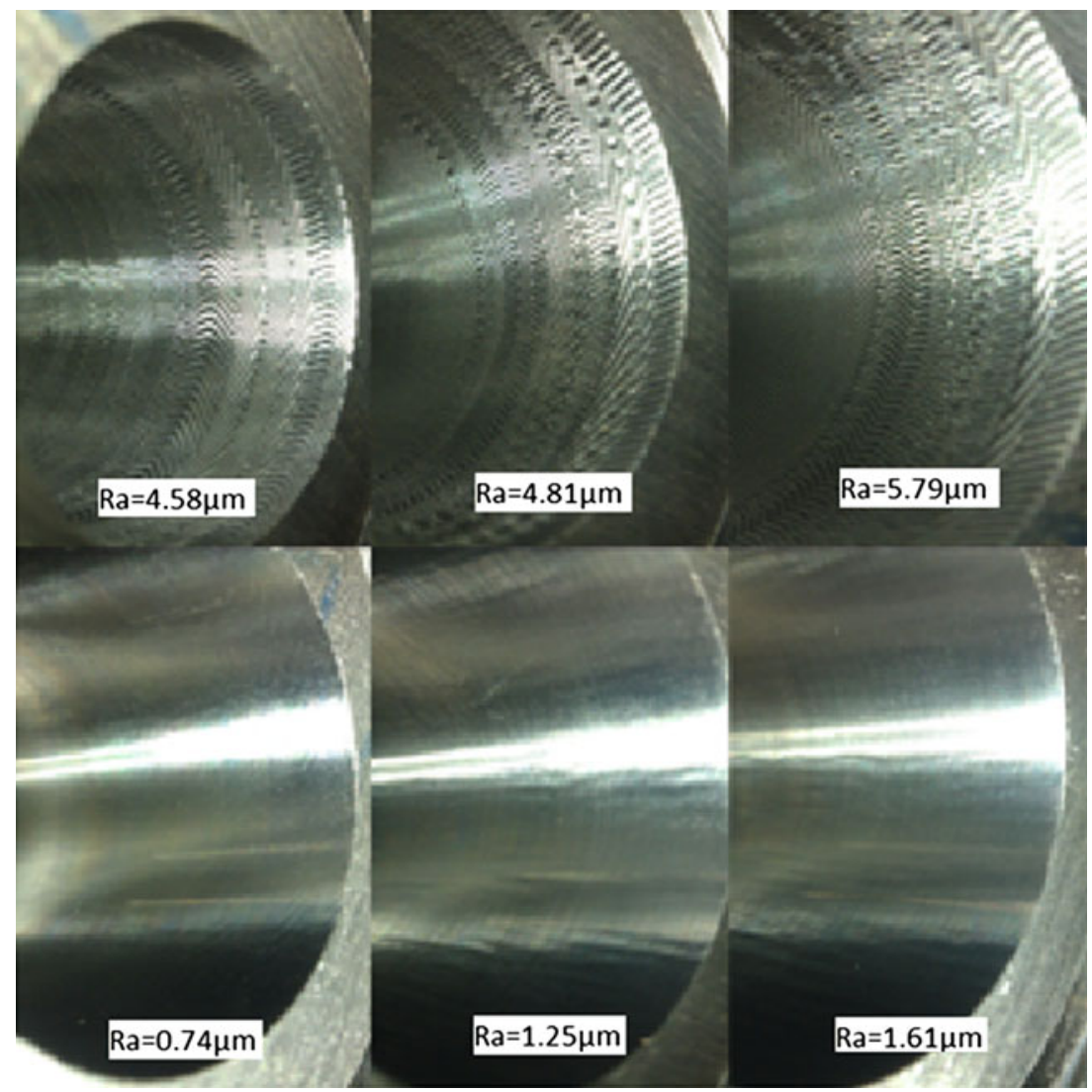

Fig. 10 Surface finish of the workpiece after machining using the conventional, uncoated tool (top), as well as the coated tool (bottom). The depth of cut was in all cases $0.5 \mathrm{~mm}$ and the same cutting sequence was repeated three times for each tool. The surface roughness value is an averaged value of measurements at three different points

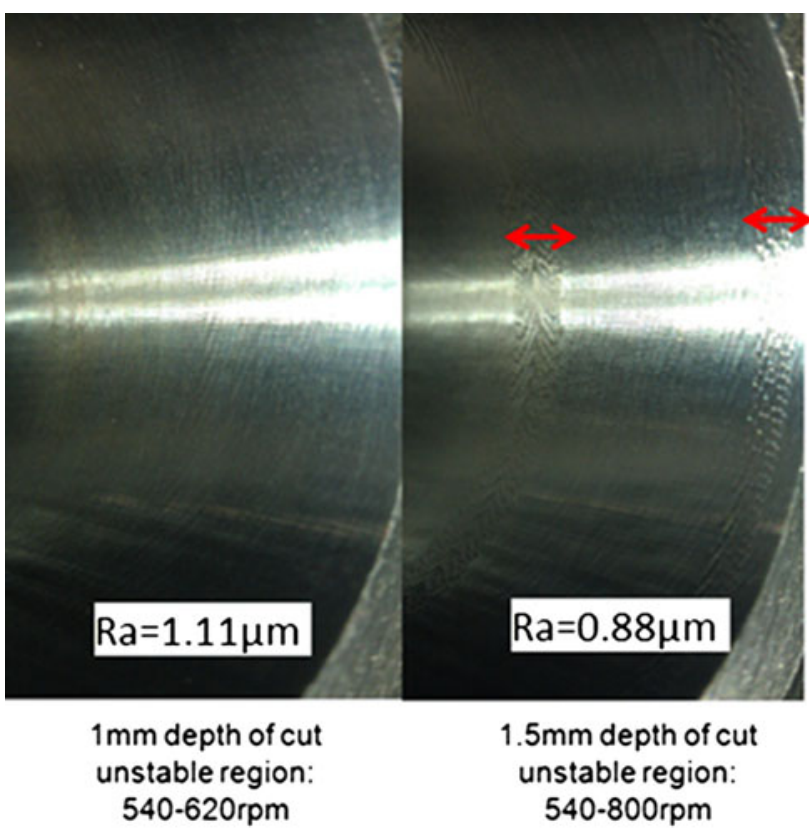

Fig. 11 The surface finish of the coated tool with $1 \mathrm{~mm}$ depth of cut (left) and $1.5 \mathrm{~mm}$ depth of cut (right), the surface roughness value is an averaged value of measurement at three different points. The red arrows indicated areas where unstable cutting operation was observed and hence leading to increased surface roughness for those particular regions
When a clamping interface is applied, such as clamping by screws, the internal damping of a cutting tool will usually increase due to interface damping effects (Ref 36). By applying high damping capacity materials in the clamping area, the internal damping of a mechanical structure will be improved even further. This is due to the concentration of vibration strain energy in clamping area, see Fig. 13. The concentrate the strain energy in the regions where high damping material applied, the energy dissipation in the damping material can be enhanced (Ref 39).

While the tool is under cyclic bending motion, a shear motion will arise in the clamping area because of the constraining fixture (Ref 39). If a damping material has been applied in the clamping area and the cyclic shear strain is induced during the vibrating movement, the damping effect of the material under shear strain will absorb the energy of vibration and transfer that energy into heat. Thus, the damping capacity in the cutting process will be enhanced.

The reason for such a good damping material has so far not been fully established, but it is here speculated that the columnar structure of the material has a beneficial effect on the shear strain (Ref 39) in the clamping area, since it can enhance the internal friction between the boundaries of the different columns, meaning that the mechanical vibration energy is transformed into shear strain energy and finally into heat by the frictional motion of the individual columns in the coating. These ideas are in line with the work of Suhr et al. (Ref 18), where it is reported that the damping capacity of a material is 
strongly related to the internal boundaries between different small domains, and as such can be enhanced by increasing the surface area to volume ratio. Pulickel et al. (Ref 40) had studied the effect of damping while mixing the carbon nanotubes in polymers and pointed out that the interface slippage injects the damping into composite systems. The load transfer mechanism is critical for both material's storage modulus and damping. The
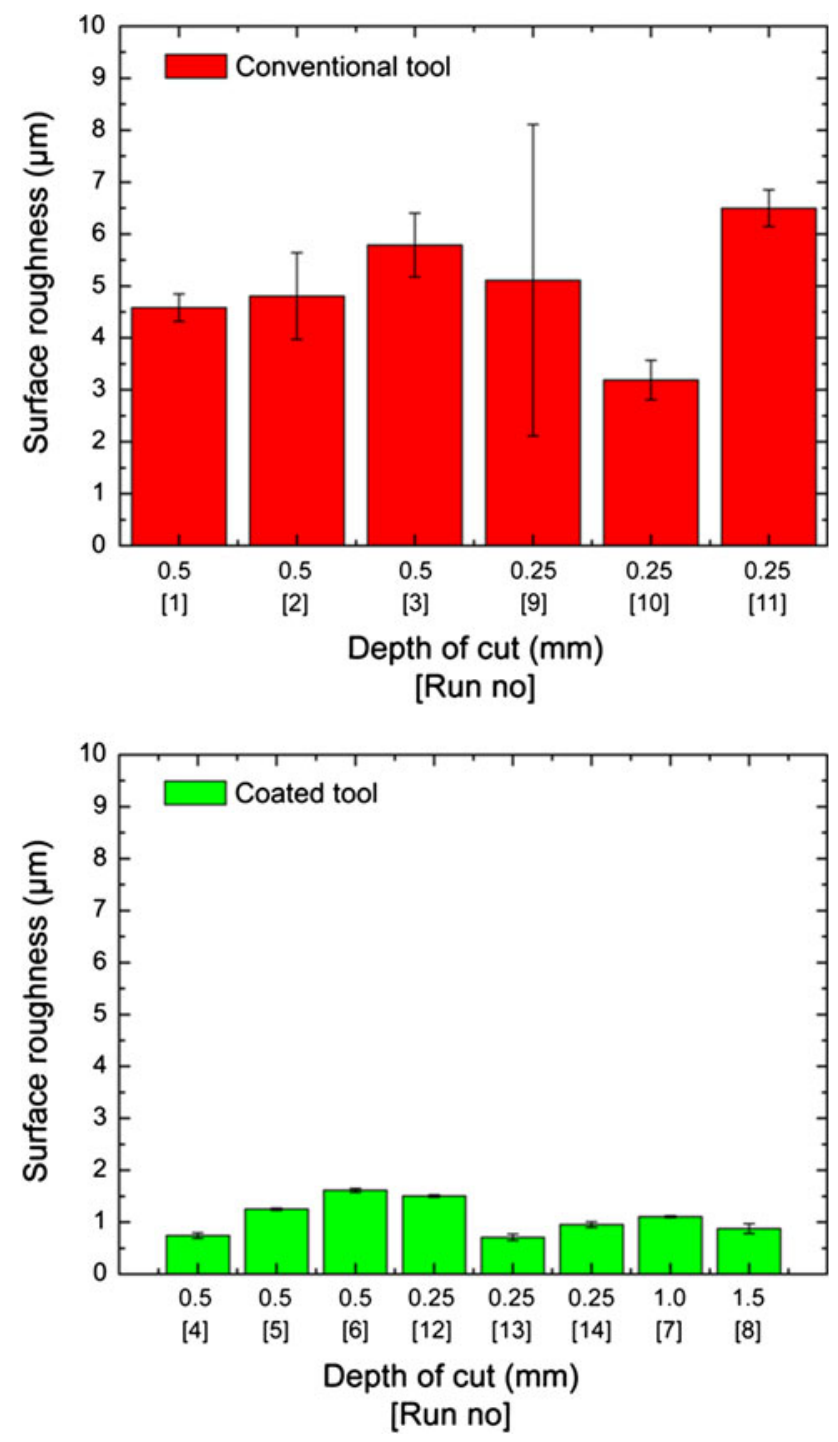

Fig. 12 The measured $R a(\mu \mathrm{m})$ values for both the uncoated tool and the coated tool. The process parameters are found in Table 2 for each run number slippage phenomenon in grain boundary interfaces would result in poor load transfer while gaining higher damping factor (Ref 40). These results conform with Asthana (Ref 41) who discussed the damping mechanism in cast iron and metalmatrix composites. However, the author (Ref 41) holds a different opinion of damping mechanism in cast iron, while the author states that the major mechanism of vibration energy dissipation is within the graphite flakes themselves and not in the graphite-matrix interface.

In addition, through SEM picture at high resolution (as shown in Fig. 14) we also observed that smaller domains of carbon-containing particles are found inside the columnar structures. These nano scaled domains will most likely increase the damping effect, since it has previously been reported that graphite inclusions can be used to effectively dissipate vibrational energy under cyclic bending (Ref 21). The working principle is that the non-uniform distribution of graphite inclusions will undergo plastic deformation in the individual micro volumes of the coating when subjected to cyclic loading, which results in a non-uniform stress distribution due to elastic and plastic anisotropy of the randomly oriented inclusions (Ref 42). Through this micro plastic deformation, occurring at a large number of sites simultaneously, it is possible to effectively dissipate vibration energy. Furthermore, Golovin et al. (Ref 21), argue that flake-like graphite micro inclusions are more effective vibration dampers compared to spherical structures, which, by tailoring the morphology of the present coating, could be a possible route towards optimizing the damping capacity reported here. However, this will be the subject of a future study.

\subsection{Advantages of the PECVD Process}

The damping mechanism in the material is mainly from the internal friction in the grain boundary interfaces (Ref 19, 21), and the load transfer mechanism is critical for controlling the material's strength and damping property (Ref 41, 43). Grain interface formation depends on the temperature of conventional annealing process. The PECVD is beneficial while it can manipulate the size of precipitated nano particles and formation of grain interfaces through control the process parameters, such as power density, plasma density, substrate biasing, and process pressure. Instead of controlling the deposited materials' structure and properties through adjust substrate heating in conventional thermal CVD process, the bias voltage controls the deposited materials' structure and properties (Ref 44). Heating of the substrate can be removed for PECVD process to overcome the melting issue. In this study, optimization of the materials' internal interfaces property for its damping purpose has not been delivered, and this will be done in the future work.

Table 3 Summary of the surface roughness measurements in the clamping area

\begin{tabular}{|c|c|c|c|c|c|c|c|c|c|c|c|c|}
\hline & \multicolumn{3}{|c|}{ Measurement 1} & \multicolumn{3}{|c|}{ Measurement 2} & \multicolumn{3}{|c|}{ Measurement 3} & \multicolumn{3}{|c|}{ Averaged } \\
\hline & $\begin{array}{l}R a \\
(\mu \mathrm{m})\end{array}$ & $\begin{array}{c}R z \\
(\mu \mathrm{m})\end{array}$ & $\begin{array}{c}R q \\
(\mu \mathrm{m})\end{array}$ & $\begin{array}{c}R a \\
(\mu \mathrm{m})\end{array}$ & $\begin{array}{c}R z \\
(\mu \mathrm{m})\end{array}$ & $\underset{(\mu \mathrm{m})}{R q}$ & $\begin{array}{c}R a \\
(\mu \mathrm{m})\end{array}$ & $\begin{array}{c}R z \\
(\mu \mathrm{m})\end{array}$ & $\underset{(\mu \mathrm{m})}{R q}$ & $\begin{array}{c}R a \\
(\mu \mathrm{m})\end{array}$ & $\begin{array}{c}R z \\
(\mu \mathrm{m})\end{array}$ & $\begin{array}{c}R q \\
(\mu \mathrm{m})\end{array}$ \\
\hline Collet inner surface & 0.54 & 4.48 & 0.76 & 0.51 & 3.68 & 0.67 & 0.48 & 3.58 & 0.64 & 0.51 & 3.91 & 0.69 \\
\hline Conventional uncoated tool & 0.49 & 4.24 & 0.65 & 0.46 & 3.47 & 0.60 & 0.30 & 2.27 & 0.38 & 0.42 & 3.33 & 0.54 \\
\hline Coated tool & 0.62 & 4.12 & 0.77 & 0.61 & 4.56 & 0.79 & 0.55 & 4.21 & 0.72 & 0.59 & 4.30 & 0.76 \\
\hline
\end{tabular}




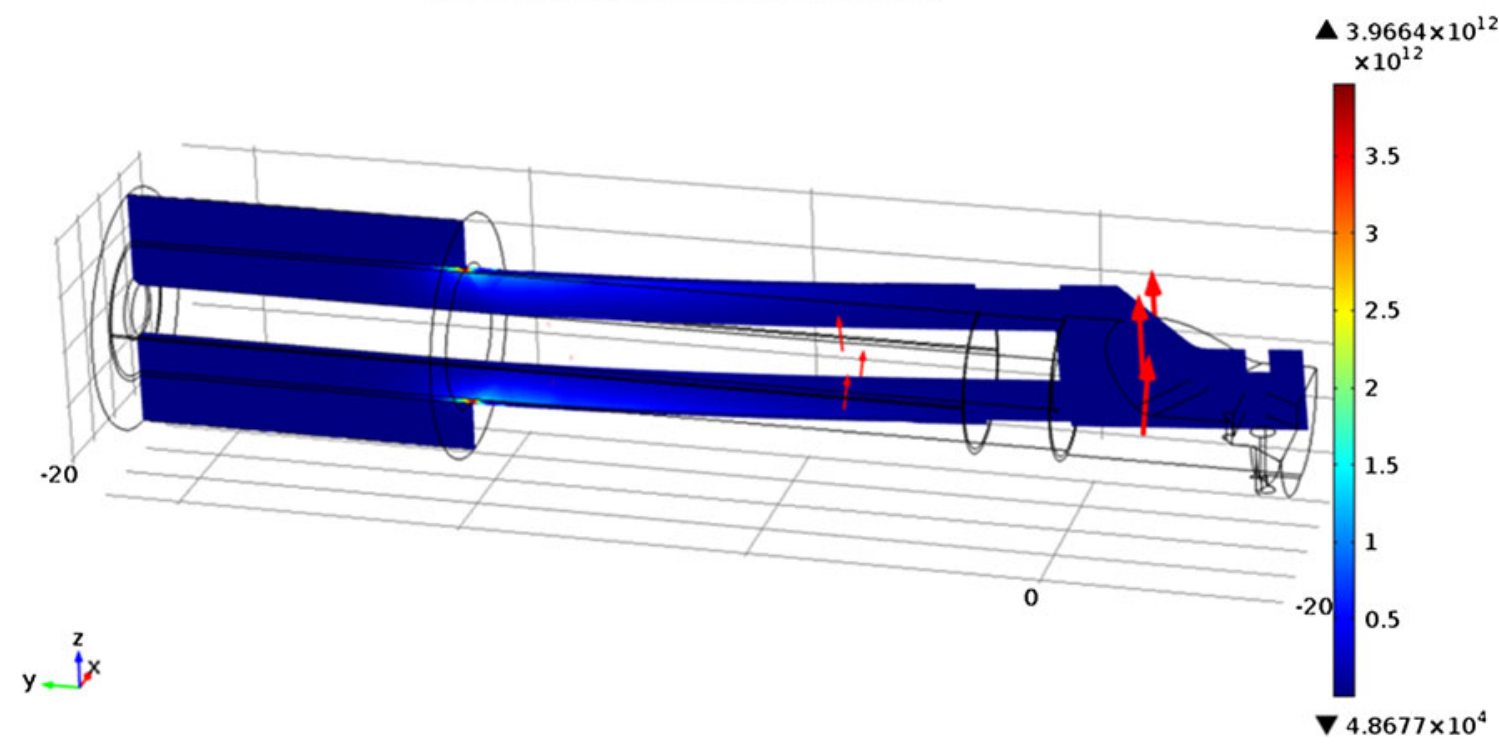

Fig. 13 The strain energy density distribution of a cutting tool clamped in a fixture while vibrating

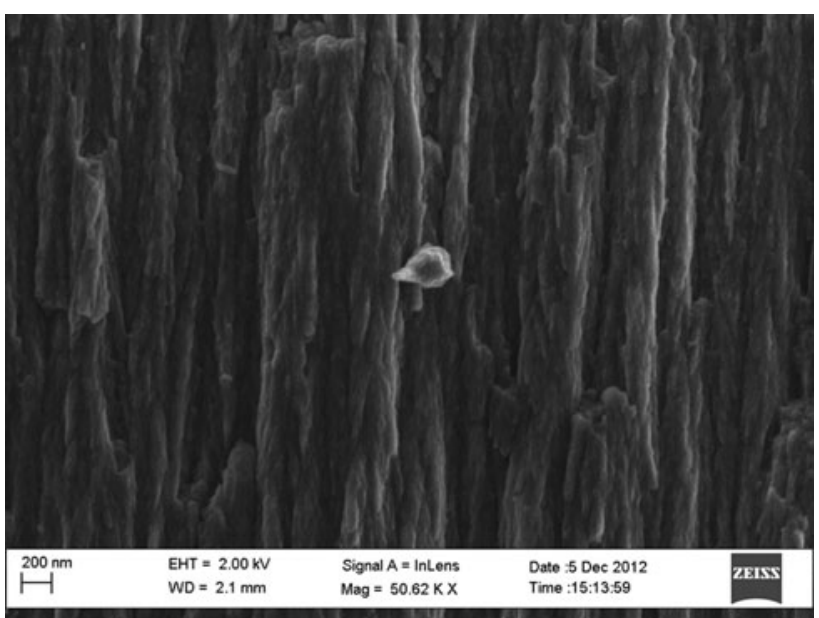

Fig. 14 The cross-section SEM picture of the carbon-based nano composite material

\section{Conclusions}

In this work, we have synthesized a new carbon-based nanocomposite coating exhibiting promising damping properties when subjected to mechanical vibrations. The coating was applied on a standard round-shank boring bar used for internal turning and tested by machining with spindle speeds in the range between 640 and $960 \mathrm{rpm}$. Comparisons between an uncoated and a coated tool were carried out at 0.25 and $0.5 \mathrm{~mm}$ depth of cut using a five times overhang, which are typical conditions known to generate detrimental mechanical vibrations. From sound pressure measurements it was concluded that the measured absolute sound level during process could be reduced by about $90 \%$ by using the coated tool. Surface roughness measurements of the processed workpiece showed decreased $R a$ values from approximately 3-6 $\mu \mathrm{m}$ to less than $2 \mu \mathrm{m}$ (and in $50 \%$ of the cases $<1 \mu \mathrm{m}$ ) when comparing an uncoated standard tool with its coated counterpart.

From the damping point of view, the reported coating differs from other types of damping application, such as tuned mass damping and constrained viscoelastic material damping, since it can easily be applied on a standard tool using the above presented coating deposition method. In addition, unlike viscoelastic materials with an elastic modulus around $10 \mathrm{MPa}$, the overall loss of rigidity will only slightly be modified by adding the carbon-based coating, since it has an elastic modulus of about $9 \mathrm{GPa}$. Last, the carbon-based coating is also considerably less sensitive to high operating temperatures due to its metallic properties as compared to polymers used for damping.

Finally, it is concluded that the vast domain of these types of carbon-based coatings is far from being completely explored. A common failure in machine structure is the unscontrollable vibration issue while there is a demand trend for deliver the same mechanical function with light structure and thin wall components. The well-known product sections where the vibration damping solution is needed include turbine blades, airplane wings, ball bearings, brake disk, and car bodies, etc. The creation of nano scale clusters that give the deposited layer unique mechanical properties can likely be further tailored to optimize the damping properties. Also, the inclusion of different metal elements during the deposition process can provide another possibility to tune the damping capability as well as the elastic modulus.

\section{Acknowledgments}

The authors wish to thank the late Dr. Vladmir Kouznetsov, who initiated the idea together with Professor Cornel-Mihai Nicolescu to introduce damping coating layers by mixing carbon 
nano-particles in a metal matrix. This study was supported by Vinnova, Sweden, under the project Eurostars E!4329 NanoComfort.

\section{References}

1. Y. Altintas and E. Budak, Analytical Prediction of Stability Lobes in Milling, CIRP Annals: Manufacturing Technology, 1995, 44, p $357-$ 362

2. S.A. Tobias and W. Fishwick, Theory of Regenerative Machine Tool Chatter, The Engineer, 1958, 205, p 199-203

3. G. Quintana and C. Joaquim, Chatter in Machining Processes: A Review, Int. J. Mach. Tools Manuf., 2011, 51, p 14

4. A.R. Yusoff, S. Turner, C.M. Taylor, and N.D. Sims, The Role of Tool Geometry in Process Damped Milling, Int. J. Adv. Manuf. Technol., 2010, 50, p 883-895

5. A. Rashid and C.M. Nicolescu, Design and Implementation of Tuned Viscoelastic Dampers for Vibration Control in Milling, Int. J. Mach. Tools Manuf., 2007, 48, p 1036-1053

6. E. Marui, S. Ema, M. Hashimoto, and Y. Wakasawa, Plate Insertion as a Means to Improve the Damping Capacity of a Cutting Tool System, Int. J. Mach. Tools Manuf., 1998, 38, p 12

7. J.H. Wang and K.N. Lee, Suppression of Chatter Vibration of a CNC Machine Centre-An Example, Mech. Syst. Signal Process., 1996, 10, p 551-560

8. L. Daghini, A. Andreas, and C.M. Nicolescu, Design, Implementation and Analysis of Composite Material Dampers for Turning Operations, International Conference on Mechanical Engineering, Tokyo, Japan, 2009

9. M.H. Miguélez, L. Rubio, J.A. Loya, and J. Fernández-Sáez, Improvement of Chatter Stability in Boring Operations with Passive Vibration Absorbers, International Journal of Mechanical Science, 2010, 52, p 1376-1384

10. S.E. Semercigil and L.A. Chen, Preliminary Computations for Chatter Control in End Milling, J. Sound Vib., 2002, 249, p 622-633

11. L.N.Ld. Lacalle and A. Lamikiz, Machine Tools for High Performance Machining, Springer, London, 2008

12. N. Olgac and M. Hosek, A New Perspective and Analysis for Regenerative Machine Tool Chatter, Int. J. Mach. Tools Manuf., 1998, 38, p 783-798

13. M.-S. Hong, K.F. Ehmann, and C.-H. Chiou, The Feasibility of Eigenstructure Assignment for Machining Chatter Control, Int. J. Mach. Tools Manuf., 2003, 43, p 1603-1620

14. L. Garibaldi and H.N. Onah, Viscoelastic Material Damping Technology, Becchis Osiride, Torino, 1996

15. D.I.G. Jones, Handbook of Viscoelastic Vibration, Wiley, New York, 2001

16. J. Suhr, N. Koratkar, P. Keblinski, and P. Ajayan, Viscoelasticity in Carbon Nanotube Composites, Nat. Mater., 2005, 4, p 134-137

17. N. Koratkar, W. Bingqing, and A.M. Pulickel, Carbon Nanotube Films for Damping Applications, Adv. Mater., 2002, 14, p 997-1000

18. J. Suhr, K.A. Nikhil, Y. Dexian, and L. Toh-Ming, Damping Properties of Epoxy Films with Nanoscale Fillers, J. Intell. Mater. Syst. Struct., 2006, 17, p 255-261

19. U.K. Vaidya, P.K. Raju, and W. Kowbel, Material Damping Studies in Carbon-Carbon Composites, Carbon, 1992, 30, p 925-929

20. M. Zeng, S.W. Or, and H.L.W. Chan, Ultrahigh Anisotropic Damping in Ferromagnetic Shape Memory Ni-Mn-Ga Single Crystal, J. Alloys Compd., 2009, 493, p 565-568
21. S.A. Golovin, V.A. Kuzmenko, G.D. Petrushin, N.N. Pis'mennyl, and I.I. Renne, Damping Capacity of Cast Iron with Different Shapes of Graphite Inclusions, Strength Mater., 1980, 12, p 360-363

22. Kouznetsov V, Nicolescu CM, Meza O, Hemmingsson L, Method, Material and Apparatus for Enhancing Dynamic Stiffness. Patent No. WO 2008105736 A2, 2008

23. L. Martinu, O. Zabeida, J.E. Klemberg-Sapieha, and P.M. Martin, Handbook of Deposition Technologies for Films and Coatings, 3rd ed., Elsevier, Amsterdam, 2010

24. D. Lundin and S. Kostas, An Introduction to Thin Film Processing Using High-Power Impulse Magnetron Sputtering, J. Mater. Res., 2012, 27, p 13

25. K. Vladmir, N. Mihai, H. Åke, and K. Klim, Plasma Activated Chemical Vapor Deposition Method and Apparatus Therefor, US 2011/ 0081477 A1, 7 Apr 2011, June 18, 2009

26. B. Angleraud and P.Y. Tessier, Improved Film Deposition of Carbon and Carbon Nitride Materials on Patterned Substrates by Ionized Magnetron Sputtering, Surf. Coat. Technol., 2004, 180-181, p 59-65

27. N. A. Ruud, R. Karlsen, K. Sørby, and C. Richt, Minimizing Vibration Tendencies in Machining. Modern Machine Shop, 2003, 19 Mar 2003

28. Mistubish, Technical Data, ed

29. S. Kosaraju, V. Gopal. Anne, and Venkateswara Rao, Ghanta; Effect of Rake Angle and Feed Rate on Cutting Forces in an Orthogonal Turning Process, Trends in Mechanical and Industrial Engineering (ICTMIE'2011), Bangkok, 2011

30. M. Sortino, G. Totis, and F. Prosperi, Development of a Practical Model for Selection of Stable Tooling System Configurations in Internal Turning, Int. J. Mach. Tool Manuf., 2012, 61, p 58-70

31. M.M. Nigm, A Method for the Analysis of Machine Tool Chatter, Int. J. Mach. Tool Des. Res., 1981, 21, p 251-261

32. L. Andren, L. Håkansson, A. Brandt, and I. Claesson, Identification of Motion of Cutting Tool Vibration in a Continuous Boring OperationCorrelation to Structural Properties, Mech. Syst. Signal Process., 2004, 18, p 903-927

33. H. Akaike and Y. Yamanouchi, On the Statistical Estimation of Frequency Response Function, Ann. Inst. Stat. Math., 1962, 14, p 56-89

34. M. Russ, Sound Synthesis and Sampling, Elsevier Ltd., Oxford, UK/ Burlington, USA, 2009

35. Turning Guidance, Technical Guidance, Ed.: Sumitomo Electric, p 12

36. Y. Ito, Modular Design for Machine Tools, Part 2, McGraw-Hill Companies, New York, 2008

37. N7, Surface Finish N Grades Per ISO 1302/1992 N1 N2 N3 N4 N5 N6 N7 N8 ed

38. B. Azvinet, G.R. Tomlinsont, and R.J. Wynnet, Use of Active Constrained-Layer Damping for Controlling Resonant, Smart Mater. Struct., 1994, 4, p 1-6

39. M.D. Rao, Recent Applications of Viscoelastic Damping for Noise Control in Automobiles and Commercial Airplanes, J. Sound Vib., 2003, 262, p 457-474

40. P.M. Ajayan, J. Suhr, and N. Koratkar, Utilizing Interfaces in Carbon Nanotube Reinforced Polymer Composites for Structural Damping, J. Mater. Sci., 2006, 41, p 7824-7829

41. R. Asthana, Properties of Cast Composites, Key Eng. Mater, 1998, 115-152, p 351-398

42. S.A. Golovin, I.I. Renne, and G.D. Petrushin, Peculiarities of the Distribution of Local Microdeformations in Cast Iron with Different Forms of Graphite, Strength Mater., 1979, 11, p 1421-1424

43. R. Asthana, Interfaces in Cast Composites, Key Eng. Mater, 1998, 151-152, p 301-350

44. A. Grill, Diamond-like Carbon: State of the Art, Diam. Relat. Mater, 1999,8, p $428-434$ 